\title{
Estrogen Iontophoresis Versus Stem Cell Therapy in the Treatment of Chronic Wound in the Lower Limb
}

\author{
ADEL A. NOSSEIR, Ph.D.*; WAFAA H. BORHAN, Ph.D.*; WAEL ABO EL-KHER, M.D.** and \\ ISLAM M. KAMEL, M.Sc.*** \\ The Department of Physical Therapy for Surgery, Faculty of Physical Therapy, Cairo University*, \\ The Department of Microbiology \& Immunology, Egyptian Military Medical Academy** and The Department of Physical \\ Therapists, El-Maady Military Hospital***
}

\begin{abstract}
Background: Chronic non-healing ulcers present a challenging and demanding scenario to the physical therapists and physician. Over the past decade, new adjuvants for wound healing have been developed that have become readily available to the wound care practitioner.

Purpose: To determine and compare between the effectiveness of estrogen iontophoresis as physical therapy modality and stem cell therapy in the treatment of diabetic foot ulcers.

Methods: Forty-five patients who had diabetic foot ulcers for longer than three months. Their ages were ranged from 40-50 years; with mean value $45.99 \pm 4.147$ years. The patients were selected from El-Maady Military Hospital (Department of General Surgery)in the period between Jan. 2015 and Dec. 2016. Patients who met the selection criteria were divided randomly into three equal groups, Group (A) received estradio iontophoresis (-ve ) electrode by intensity $1-5 \mathrm{~mA}$ for $10 \mathrm{~min}$, 3 sessions per week for 4 weeks and medical treatment. Group (B) received stem cell therapy for wound and estradiol that transmitted through iontophoresis $(-\mathrm{ve})$ electrode for 4 weeks. Group (C) received stem cell therapy (using bone marrow-derived fibrocytes).
\end{abstract}

Measurements: Wound Surface Area (WSA) was assessed by Digital Camera and Image J 1.49. V Computer Software, and wound volume using volumetric method were assessed before treatment and after 4 weeks of treatment.

Results: The findings of this study indicated significant decrease in WSA and wound volume after treatment in al groups $\mathrm{A}, \mathrm{B}$ and $\mathrm{C}(p<0.0001)$. There was significant difference between Group B and C after treatment in WSA and wound volume (with favored results in Group B.

Conclusion: Results showed that estrogen iontophoresis for 4 weeks in combination with stem cell is an effective adjuvant therapy, better that each method alone, in treatment of diabetic foot ulcers through accelerating wound healing and reducing WSA, wound volume.

Key Words: Estrogen iontophoresis - Diabetic foot ulcers Stem cell therapy.

Correspondence to: Dr. Islam Mostafa Kamel, E-Mail: Midzaiady@gmail.com

\section{Introduction}

CHRONIC wounds such as diabetic foot ulcers, venous ulcers, and pressure ulcers are a major source of morbidity and mortality [1].

Chronic lower extremity ulcers are a major source of morbidity and health care expenditure across the world. In the last decade, numerous advanced modalities have become available that can help expedite wound healing when standard wound care modalities are unsuccessful [2]

Chronic wounds may be due to arrest of wound healing in the state of chronic inflammation, with an imbalance between protease activity and growth factor expression. The chronic wound environment has an overload of Matrix Metalloproteases (MMPs), reduced amounts of Tissue Inhibitors of MMPs (TIMPS), senescent and dysfunctional cells with decreased proliferative and synthetic activities, and shortages in growth factors and growth factor receptors. This situation suppresses fibroblasts proliferation, motility and protein production so that the wound remain in a chronic state [3]

The cost of wound care is significant. The most important components are the costs of woundrelated hospitalisation and the opportunity cost of nurse time. The $32 \%$ of patients treated in hospital accounted for $63 \%$ of total costs [4].

Impaired healing is a problematic and common complication of chronic wounds. Although laser has been used in the treatment of chronic wounds with promising efficacy, its mechanism is still poorly characterized [5]. 
The present study was designed to determine and compare between the effectiveness of estrogen iontophoresis as physical therapy modality and stem cell therapy in the treatment of diabetic foot ulcers.

\section{Material and Methods}

A statistical power analysis suggested that sample size above 15 participants per group were required to achieve more than $80 \%$ power. Forty five patients who have chronic unhealed lower limb ulcers for longer than three months, with different causes (diabetic foot ulcer, pressure ulcer and venous leg ulcer) in the lower limb were participated in this study. Their ages were ranged from 40-50 years. The patients were selected from El-Maady Military Hospital (Department of General Surgery). In this study, the patients randomly assigned into 3 equal groups, (15 patients for each group). Group (A): Iontophoresis group, this group included 15 patients with chronic unhealed lower limb ulcers for longer than three months, with diabetic foot ulcer and they received estradiol that transmitted through iontophoresis (-ve) electrode by intensity adjusted between 1 and $5 \mathrm{~mA}$ increased very slowly until the patient reports feeling a tingling or prickly sensation for $10 \mathrm{~min}, 3$ sessions per week for 4 weeks [6]. Group (B) iontophoresis and stem cell group, this group included 15 patients with chronic unhealed lower limb ulcers for longer than three months, with diabetic foot ulcer and they received stem cell therapy for wound and estradiol that transmitted through iontophoresis ( ve) electrode, 3 sessions per week for 4 weeks. Group (C) stem cell group, this group included 15 patients with chronic unhealed lower limb ulcers for longer than three months. They received stem cell therapy (using bone marrow-derived fibrocytes) [7]

The patients were included in the study if their age between 40 to 50 years, complaining from chronic lower limb ulcers selected (diabetic foot ulcer) longer than 3 months.

Patients were excluded from this study if they had skin malignancy in the area to be treated, severe hypo or hyper tension, cardiovascular instability, renal and hepatic disorders, medical, physical, or pregnant, breast feeding, or planning pregnancy female patients.

\section{Study design and randomization:}

The study was designed as a prospective randomized clinical trial in which patients were assigned randomly into two groups. Randomization was used to eliminate the researches' bias and was carried out by a blinded and an independent research assistant who opened sealed envelopes that contained a computer generated randomization card.

\section{Measurement procedures:}

Measurement and assessment was done before the starting of treatment and at the end of treatment after 6 weeks for patients of all Groups A, B and C.

\section{A- Computerised photographic WSA assessment:}

This type of assessment is performed by using Kodak Easy share P712 Zoom Digital Camera and ImageJ 1.47. Computer Software. A square adhesive $4 X 4 \mathrm{~cm}^{2}$ in size with 16 square grids of $1 \mathrm{~cm}$ each, fixed as near as possible for the wound. An ordinary digital camera (Kodak Easy share P712 Zoom) was used for capturing a photograph for the wound (showing the adhesive $4 \times 4 \mathrm{~cm}^{2}$ square). Image J TM free open source software was used to analyze the photograph by marking the edges of the wound and calculating the number of pixels falled under the marked wound area. The edges of the square adhesive marker was marked and the number of pixels falling under the marked square adhesive marker was calculated. Since the dimensions of the square are known $\left(16 \mathrm{~cm}^{2}\right)$, it was possible to derive the exact size of the marked area of the wound by dividing the size of wound by the size of the square in the photo then multiplied by the actual size of the square $\left(16 \mathrm{~cm}^{2}\right)[8]$.

\section{$B$ - Wound volume assessment:}

This type of assessment is performed by using sterilized siring and Terramycin ointment. Filing the sterilized siring of $5 \mathrm{~cm}^{3}$ with Terramycin ointment. Then filing the wound by the kwon volume of the Terramycin ointment. It is an easy accurate method for wound volume estimation [9].

\section{Treatment procedures:}

A verbal explanation about the treatment of the research and main points of experimental procedure design was explained to every patient. The procedure of the treatment was divided to 3 main categories.

\section{A- Therapeutic procedures (preparatory treatment application):}

Patient history was taken in relation of the study. Patient was informed of the treatment and its purpose. The patient was placed in a comfortable position. Absolute and relative contraindications (mentioned in exclusion criteria) should be excluded. For the efficiency of application and to save 
time, the treatment equipment was equipped and ready for use before the patient arrived.

\section{B-Procedure estradiol iontophoresis therapy:}

A solution of $0.5 \%$ estradiol was used over the target zone into an absorbent rapier covered electrode (electrode for iontophoresis) the electrode is applied. The time of treatment was adjusted (for $10 \mathrm{~min})$. The intensity was adjusted to $(1-5 \mathrm{~mA})$ be increased very slowly until the patient reports feeling a tingling or prickly sensation. Then the treatment will start. Remove electrode and end treatment session [10]

\section{C-Procedures of stem cells treatment protocol:}

Fibrocytes are a distinct type of bone marrow derived cell that constitutes $0.1 \%-0.5 \%$ of peripheral blood cells; they exhibit monocyte and fibroblast-like characteristics and express stromal cell molecules such as type I-collagen, fibronectin and hematopoietic stem cell markers, such as CD11b, CD34 and CD45 [11]. Fibrocytes were discovered in 1994 due to their rapid recruitment from blood into wound chambers implanted in mice [12]

\section{Statistical analysis:}

Data were collected before initiation of the treatment (pre-treatment), and after 4 weeks of treatment (post-treatment). Statistical analysis was conducted using SPSS for windows, Version 18 (SPSS, Inc., Chicago, IL). The current test involved two independent variables. The first one was the (tested group); between subjects factor which had three levels, Group A (iontophoresis group), Group B (iontophoresis and stem cell group) and Group $\mathrm{C}$ (stem cell group). The second one was the (measuring periods); within subject factor which had two levels (pre-treatment and post-treatment 6 weeks after application of treatment). In addition, this test involved two tested dependent variables (Wound Surface Area (WSA) and wound volume). Accordingly, 3 X 2 Mixed Design MANOVA was used to compare the tested variables of interest at different tested groups and measuring periods. 3 $X 2$ Mixed Design MANOVA was performed on the examined sample with the alpha level 0.05. 3 X 2 Mixed Design MANOVA was conducted to compare (Wound Surface Area (WSA) and wound volume) between both groups pre-treatment, and post-treatment. In addition, it was intended to compare between the pre-treatment and posttreatment for each variable at each tested group and finally test the interaction between the two independent variables (tested group and time factor). One way ANOVA was used for patients general characteristics comparison in between groups. Prior to final analysis, data were screened for normality assumption and presence of extreme scores. This exploration was done as a pre-requisite for parametric calculations of the analysis of difference. The level of significance was set at the 0.05 level [13] .

\section{Results}

\section{Baseline and demographic data:}

There were no statistically significant differences $(p>0.05)$ between subjects in both groups concerning age, body mass, height, and BMI (Table 1).

The results and the statistical analysis of Wound Surface Area (WSA) in various three groups of the study:

The mean \pm SD values of WSA in the "pretreatment" and "post-treatment" were $12.93 \pm 6.39$ and 6.50 \pm 5.11 respectively in the Group A. Multiple pairwise comparison tests (post hoc tests) as shown in (Table 2) revealed that there was a significant reduction of WSA among (pre versus post-treatment) $(p$-value $=0.000)$ with percentage of improvement $49.71 \%$. Group B mean \pm SD values of WSA in the "pre-treatment" and "post-treatment" were $12.97 \pm 6.94$ and $5.61 \pm 5.07$ respectively which revealed that there was a significant reduction of WSA among (pre versus post-treatment) $(p$-value $=$ 0.000 ) with percentage of improvement $56.74 \%$. Also, Group C showed significant reduction of WSA among (pre versus post-treatment $)(p$-value $=$ 0.001 ) from mean \pm SD values $12.81 \pm 6.45$ pretreatment to $9.99 \pm 3.95$ post-treatment with percentage of improvement $21.98 \%$. Between groups comparison of WSA "pre" treatment among three groups showed no significant differences as (Group A versus B), (Group A versus C) and (Group B versus $C)(p$-values $=0.678,0.606$ and 1.00$)$ respectively. After treatment WSA, multiple pairwise comparison test among three groups (Group A versus B) and (Group A versus C) showed no significant differences with $(p$-value $=1$ and 0.151$)$ respectively. While, there was significant differences between (Group B versus C) with ( $p$-value $=$ 0.046).

The results and the statistical analysis of wound volume in various three groups of the study:

The mean \pm SD values of wound volume in the "pre-treatment" and "post-treatment" were $3.31 \pm$ 1.35 and $3.31 \pm 1.35$ respectively in the Group A. Multiple pairwise comparison tests (post hoc tests) (Table 3) revealed that there was a significant reduction of wound volume among (pre versus post-treatment $)(p$-value $=0.000)$ with percentage 
of improvement in wound volume was $53.7 \%$. Group B mean \pm SD values of wound volume in the "pre-treatment" and "post-treatment" were $3.43 \pm 2.27$ and $1.20 \pm 1.10$ respectively. Multiple pairwise comparison tests (post hoc tests) (Table 3 ) revealed that there was a significant reduction of wound volume among (pre versus posttreatment $)(p$-value $=0.000)$ with percentage of improvement in wound volume was $64.97 \%$ aftertreatment application in Group B when compared with before treatment application (pre-treatment). Also, Group C As shown in (Table 7), the mean \pm SD values of wound volume in the "pre-treatment" and "post-treatment" were $3.79 \pm 1.84$ and $2.47 \pm 1.34$ respectively in the Group C. Multiple pairwise comparison tests (post hoc tests) (Table 8) revealed that there was a significant reduction of wound volume among (pre versus post-treatment) ( $p$-value $=0.000$ ) with percentage of improvement in wound volume was $34.95 \%$. Between groups comparison of wound volume, multiple pairwise comparison tests (post hoc tests) revealed that the mean values of the "pre" test between among three groups (Group A versus B), (Group A versus C) and (Group $B$ versus $C$ ) showed no significant differences with ( $p$-value $=1.00,1.00$ and 1.00) respectively.

"Post" treatment multiple pairwise comparison among three groups (Group A versus B), (Group $A$ versus $C$ ) and (Group B versus $C$ ) showed no significant differences with ( $p$-value $=1.00$ and 0.172 ) respectively. While, there was significant differences between (Group B versus C) with ( $p$ value $=0.034$ ).

Table (1): General characteristics of patients.

\begin{tabular}{|c|c|c|c|c|c|c|c|c|c|}
\hline \multirow{2}{*}{ Items } & \multicolumn{3}{|c|}{ Age (years) } & \multicolumn{3}{|c|}{ Weight (k.g) } & \multicolumn{3}{|c|}{ Height (c.m) } \\
\hline & \multicolumn{9}{|c|}{ Group (A) Group (B) Group (C) Group (A) Group (B) Group (C) Group (A) Group (B) Group (C) } \\
\hline Mean & 47.6 & 84.5 & 175.1 & 46.0 & 83.7 & 176.3 & 47.4 & 79.8 & 175.4 \\
\hline \pm S.D. & 4.2 & 8.4 & 3.0 & 3.6 & 7.2 & 2.8 & 4.6 & 8.2 & \\
\hline F-value & & 0.663 & & & 1.517 & & & 0.713 & \\
\hline$p$-value & & 0.521 & & & 0.231 & & & 0.496 & \\
\hline Level of significance & & N.S. & & & N.S. & & & N.S. & \\
\hline
\end{tabular}

Table (2): Statistical analysis of the WSA pre and post-treatment for three groups of the study A, B and C.

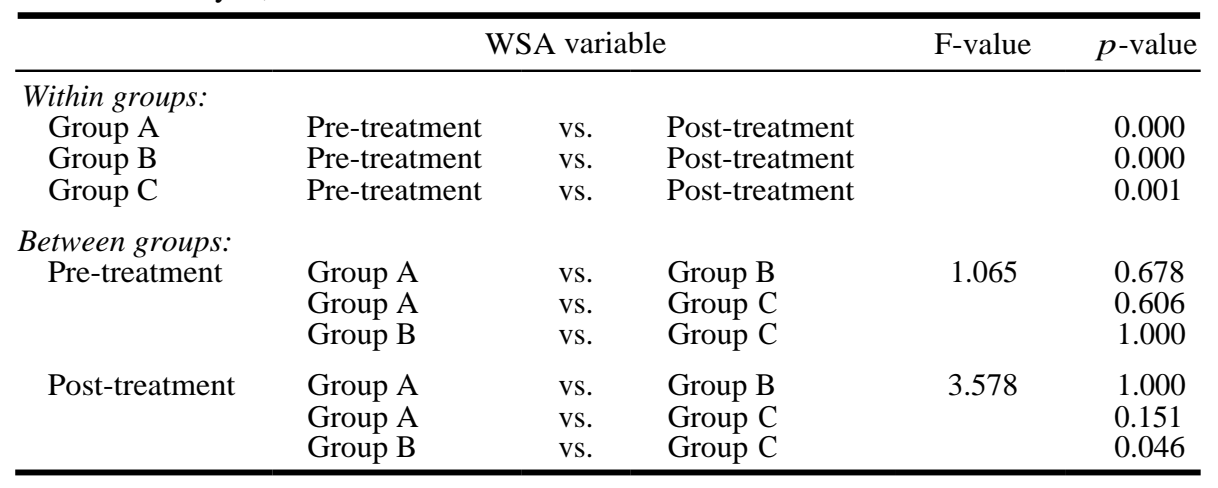

*: Significant at alpha level $<0.05$.

Table (3): Statistical analysis of the wound volume pre and post-treatment for three groups of the study A, B and C.

\begin{tabular}{|c|c|c|c|c|c|}
\hline & \multicolumn{3}{|c|}{ Wound volume variable } & \multirow[t]{2}{*}{ F-value } & $\frac{p \text {-value }}{0.000}$ \\
\hline $\begin{array}{l}\text { Within groups: } \\
\text { Group A } \\
\text { Group B } \\
\text { Group C }\end{array}$ & $\begin{array}{l}\text { Pre-treatment } \\
\text { Pre-treatment } \\
\text { Pre-treatment }\end{array}$ & $\begin{array}{l}\text { vs. } \\
\text { vs. } \\
\text { vs. }\end{array}$ & $\begin{array}{l}\text { Post-treatment } \\
\text { Post-treatment } \\
\text { Post-treatment }\end{array}$ & & $\begin{array}{l}0.000 \\
0.000 \\
0.000\end{array}$ \\
\hline $\begin{array}{l}\text { Between groups: } \\
\text { Pre-treatment }\end{array}$ & $\begin{array}{l}\text { Group A } \\
\text { Group A } \\
\text { Group B }\end{array}$ & $\begin{array}{l}\text { vs. } \\
\text { vs. } \\
\text { vs. }\end{array}$ & $\begin{array}{l}\text { Group B } \\
\text { Group C } \\
\text { Group C }\end{array}$ & 0.269 & $\begin{array}{l}1.00 \\
1.00 \\
1.00\end{array}$ \\
\hline Post-treatment & $\begin{array}{l}\text { Group A } \\
\text { Group A } \\
\text { Group B }\end{array}$ & $\begin{array}{l}\text { vs. } \\
\text { vs. } \\
\text { vs. }\end{array}$ & $\begin{array}{l}\text { Group B } \\
\text { Group C } \\
\text { Group C }\end{array}$ & 3.775 & $\begin{array}{l}1.000 \\
0.172 \\
0.034\end{array}$ \\
\hline
\end{tabular}

*: Significant at alpha level $<0.05$. 


\section{Discussion}

This current study was designed to determine and compare between the effectiveness of estrogen iontophoresis and stem cell therapy in reducing wound surface area and wound volume in treatment of chronic lower limb wound.

The parameters investigated in the present study involved: (1) Wound surface area and wound volume, these variables were measured at different times and periods pre-treatment application, and at the end of treatment after 6 weeks.

Forty-five patients with unhealed diabetic foot ulcers were assigned into 3 various groups of the study (equal in numbers). Group (A): Iontophoresis Group received estradiol that transmitted through iontophoresis (-ve) electrode [6]

Group (B) iontophoresis and stem cell group received stem cell therapy for wound and estradiol that transmitted through iontophoresis $(-\mathrm{ve})$ electrode.

Group (C) stem cell group received stem cell therapy (using bone marrow-derived fibrocytes) [7]

The pre-treatment results of the present study revealed no significant difference between the mean values of WSA and wound volume.

Results of Group (A): Iontophoresis group and Group (B) iontophoresis and stem cell group showed that:

The post-treatment results of this study showed reduction in the WSA and wound volume after the treatment for Group (A) and Group (B) with a percentage of $66.6 \%$ and respectively for WSA and $75.685 \%$ and respectively for wound volume. There was no significant difference between Group (A) and Group (B) post-treatment regarding the WSA and wound volume.

Which confirm the effectiveness of estradiol iontophoresis and estradiol iontophoresis with stem cell therapy in reducing the WSA and wound volume so improving the chronic wound healing.

This results consistent or supported by the works reported by Sunkari et al., (2014); Tomoda et al., (2012); Han et al., (2012); Khaksar et al., (2012); Campbell et al., (2010); Prentice, (2005); Essa et al., (2004); Essa et al., (2002) and Arora et al., (1998).

\section{A- Estrogen iontophoresis studies:}

Sunkari [14] concluded that Esterogen Receptor beta (ERb)-mediated signaling increased angiogenesis when is impaired in diabetic mice wound. This observation is important for potential therapeutically use of selective modulators of ER (SERM) that could be potentially used for stimulating wound healing in diabetes.

In another similar observation by Han [15] on Esterogen Receptor alpha (Era)-mediated signaling which reported to have positive vascular effects through both EPCs induction and improvement of the vascular reaction.

Khaksar [16] investigated the possible effects of systemic and topical estrogen were investigated on wound healing in normal and diabetic male rats. The results expressed that systemic and topical estrogen can improve the impaired healing of diabetic wounds.

Tomoda [17] observed higher amount of estradiol was delivered through skin when estradiol was loaded in nanoparticles than estradiol was free molecules. Also, iontophoresis was applied to enhance the permeability of nanoparticles. When iontophoresis was applied, permeability of estradiol-loaded PLGA nanoparticles was much higher than that obtained by simple diffusion of them through skin, since they have negative surface charges. They were found to penetrate through follicles mainly. Also, enhanced permeability effect of estradiol by using nanoparticle system and iontophoresis were observed in vivo. The combination of charged nanoparticle system with iontophoresis is useful for effective transdermal delivery of therapeutic agents.

Prentice [18] reported that iontophoresis decreases the absorption lag time, while it increases the delivery rate when compared with passive skin application.

Essa et al., [10] stated that Iontophoresis $(0.8 \mathrm{~mA} /$ $\mathrm{cm}^{2}$, for $8 \mathrm{~h}$ ) improved drug penetration over passive delivery for all systems, with ultra-deformable vesicles performing best although the penetration parameters of estradiol from ultra-deformable vesicles were higher than those from traditional liposomes.

Essa [19] concluded that estradiol iontophoresis (up to $0.8 \mathrm{~mA} / \mathrm{cm}^{2}$ ) further promoted delivery of estradiol by the liposomal structure in a proportional fashion i.e. increased current densities raised fluxes. Such improvements may be due to high deformability of the vesicular membrane that enables the 
liposomes to penetrate intact through the skin, and/or the negative charge on the vesicular surface.

Arora [20] examined the effect of estrogen on endothelium-dependent relaxation in the cutaneous microcirculation of women. Results indicate that estrogens might enhance endothelium-dependent and endothelium-independent vasodilatation in the microcirculation of women.

Results of Group $(C)$ : Stem cell group showed that, the post-treatment results of this study showed reduction in the WSA and wound volume after the treatment for Group (C) with a percentage of $66.6 \%$ for WSA and $75.685 \%$ for wound volume. There was significant difference between Group (C) and Group (B) post-treatment regarding the WSA ( $p$ value $=0.046)$ and wound volume $(p$-value $=0.034)$ with favour results in Group B. There was no significant difference between group B and Group $\mathrm{C}$ in WSA and wound volume.

Which confirm the effectiveness of bone marrow derived stem cell therapy in reducing the WSA and wound volume so improving the chronic wound healing.

\section{B- Bone marrow derived stem cells:}

Human mesenchymal stem cells derived from bone marrow are relatively easy to obtain and have received considerable attention. They are selfrenewing and capable of differentiating into various tissues and cells, such as liver epithelium, lung, gastrointestinal tract, and skin cells [21]. Bone marrow-derived cells, used in chronic wounds, have been of particular interest.

Fathke [22] showed, in the chimeric mouse model, that distant bone marrow-derived cells contribute to the reconstitution of the dermal fibroblast population in cutaneous wounds.

Ichioka [23] investigate the effect of collagen matrix impregnated with bone marrow on wound healing angiogenesis in an effective microcirculatory model and to describe our clinical experience. Bone marrow stroma cells were further found to synthesize higher amounts of collagen, FGF, and VEGF, when compared to native dermal fibroblasts, indicating a potential use in accelerating wound healing. The effects of bone marrow impregnated collagen on wound healing were studied in a microcirculatory mouse model, showing significant increases in angiogenesis. Patients with chronic leg ulcera demonstrated successful wound closure after a treatment with these impregnated collagen matrices.
Falanga [24] utilized a fibrin polymer spray to apply cultured autologous mesenchymal stem cells obtained from bone marrow aspirates to accelerate the rate of healing of acute and non-healing cutaneous wounds in both humans and mice. This approach may represent a feasible method for introducing cells into wounds.

$\mathrm{Wu}$ [25] examined the benefit of Bone Marrowderived Mesenchymal Stem Cells (BM-MSCs) in wound healing. Using an excisional wound splinting model, BM-MSCs significantly enhanced wound healing in normal and diabetic mice compared with that of allogeneic neonatal dermal fibroblasts or vehicle control medium. Thus, study suggest that BM-MSCs promote wound healing through differentiation and release of proangiogenic factors.

Hocking and Gibran [26] review the growing evidence demonstrating the promise of Multipotent Mesenchymal Stem/stromal (MSCs) for the treatment of impaired wound healing. MSC treatment of acute and chronic wounds results in accelerated wound closure with increased epithelialization, granulation tissue formation and angiogenesis. Although there is evidence for MSC differentiation in the wound, most of the therapeutic effects are likely due to MSCs releasing soluble factors that regulate local cellular responses to cutaneous injury. Important challenges need to be overcome before MSCs can be used effectively to treat wounds that are slow to heal.

Arno [27] examined the effects of human Wharton's Jelly-derived MSCs (WJ-MSCs) paracrine signaling on normal skin fibroblasts in vitro, and in an in vivo preclinical model. Human WJ-MSCs and normal skin fibroblasts were isolated from donated umbilical cords and normal adult human skin. Fibroblasts were treated with WJ-MSCconditioned medium (WJ-MSC-CM) or nonconditioned medium. Under our experimental conditions, WJ-MSCs enhanced skin wound healing in an in vivo mouse model.

Ribeiro [28] tested the local application of human MSCs (hMSCs) isolated from the umbilical cord Wharton's jelly together with a poly (vinyl alcohol) hydrogel (PVA) membrane, to promote wound healing in two dogs that were referred for clinical examination at UPVET Hospital, showing nonhealing large skin lesions by the standard treatments. The wounds were infiltrated with 1000 cells $/ \mu 1 \mathrm{hMSCs}$ in a total volume of $100 \mathrm{pm} \mathrm{cm}^{2}$ of lesion area. A PVA membrane was applied to completely cover the wound to prevent its dehy- 
dration. Both animals after the treatment demonstrated a significant progress in skin regeneration with decreased extent of ulcerated areas confirmed by histological analysis.

Meneses [29] performed a prospective pilot study to evaluate safety and feasibility of Bone Marrow Mononuclear Cells (BMMC) implantation in patients with Sickle Cell Disease (SCD) and Chronic Leg Ulcers (SCLU). Ulcer closure, recurrence and local pain were evaluated. In conclusion, BMMC implantation is a feasible and safe procedure, showing favourable outcomes for the treatment of SCLU, and encouraging further controlled clinical trials.

Otero-Viñas and Falanga [30] confirm the effectiveness of therapy with Mesenchymal Stem Cells (MSCs) is attractive due to their differentiating potential, their immunomodulating properties, and their paracrine effects. New technologies (including growth factors and skin substitutes) are now widely used for stimulating wound healing. However, in spite of these advances, the percentage of complete wound closure in most clinical situations is around $50-60 \%$.

\section{Conclusions:}

The results of current study showed that estrogen iontophoresis therapy for 4 weeks is an effective adjuvant therapy in treatment of unhealed diabetic foot ulcers through accelerating wound healing, reducing Wound Surface Area (WSA) and wound volume.

The results of current study showed that stem cell therapy is an effective adjuvant therapy in treatment of unhealed diabetic foot ulcers through accelerating wound healing, reducing Wound Surface Area (WSA) and wound volume.

The results of current study showed that combination between estrogen iontophoresis therapy and stem cell therapy is the most effective in comparison to use of either method alone in treatment of unhealed diabetic foot ulcers through accelerating wound healing, reducing Wound Surface Area (WSA) and wound volume.

So it could be concluded that there was greater improvement after application of estrogen iontophoresis (Group A), estrogen iontophoresis and stem cell (Group B) therapy and stem cell therapy alone (Group C) with best results in Group B and so enhancing the treatment of diabetic foot ulcers by decreasing the WSA and wound volume.

\section{References}

1- GOLINKO M.S., CLARK S., RENNERT R., FLATTAU A., BOULTON A.J. and BREM H.: Wound emergencies: The importance of assessment, documentation, and early treatment using a wound electronic medical record. Ostomy/wound management, 55: 54, 2009.

2- FRYKBERG R., TIERNEY E., TALLIS A. and KLOTZBACH T.: Cell proliferation induction: Healing chronic wounds through low-energy pulsed radiofrequency. The International Journal of Lower Extremity Wounds, 8: 45$51,2009$.

3- ERIN MARTIN D., EDWARD TIERNEY D., ARTHUR TALLIS D. and ROBERT G.F.: Use of human fibroblast derived dermal substitute (hfdds) to close a complex chronic wound in the presence of peripheral arterial disease, 5: 39-43, 2013.

4- VOWDEN K., VOWDEN P. and POSNETT J.: The resource costs of wound care in bradford and airedale primary care trust in the uk. Journal of wound Care, 18: 93-8, 2009.

5- LI Q., KAO H., MATROS E., PENG C., MURPHY G.F. and GUO L.: Pulsed radiofrequency energy accelerates wound healing in diabetic mice. Plastic and Reconstructive Surgery, 127: 2255-62, 2011.

6- ANDERSON C.R., MORRIS R.L., BOEH S.D., PANUS P.C. and SEMBROWICH W.L.: Effects of iontophoresis current magnitude and duration on dexamethasone deposition and localized drug retention. Physical Therapy, 83: 161-70, 2003

7- VARKEY M., DING J. and TREDGET E.: The potential role of stem cells in wound healing. Wounds UK, 9: 606, 2013.

8- SHETTY R., SREEKAR H., LAMBA S. and GUPTA A.K.: A novel and accurate technique of photographic wound measurement. Indian Journal of Plastic Surgery: official publication of the Association of Plastic Surgeons of India, 45: 425, 2012.

9- GOLDMAN R.J. and SALCIDO R.: More than one way to measure a wound: An overview of tools and techniques. Advances in Skin \& Wound Care, 15: 236-43, 2002.

10- ESSA E.A., BONNER M.C. and BARRY B.W.: Electrically assisted skin delivery of liposomal estradiol; phospholipid as damage retardant. Journal of Controlled Release, 95: 535-46, 2004.

11- QUAN T.E., COWPER S., WU S.P., BOCKENSTEDT L.K. and BUCALA R.: Circulating fibrocytes: Collagensecreting cells of the peripheral blood. The International Journal of Biochemistry \& Cell Biology, 36: 598-606, 2004.

12- BUCALA R., SPIEGEL L., CHESNEY J., HOGAN M. and CERAMI A.: Circulating fibrocytes define a new leukocyte subpopulation that mediates tissue repair. Molecular Medicine, 1: 71, 1994.

13- FIELD A.P.: Discovering statistics using ibm spss statistics. London: SAGE, 2013.

14- SUNKARI V.G., BOTUSAN I.R., SAVU O., GRÜNLER J., ZHENG X., GUSTAFSSON J.Å., et al.: Selective blockade of estrogen receptor beta improves wound healing in diabetes. Endocrine, 46: 347-50, 2014. 
15- HAN Y., LI X., ZHOU S., MENG G., XIAO Y., ZHANG W., et al.: 17ß-estradiol antagonizes the down-regulation of er $\alpha /$ nos-3 signaling in vascular endothelial dysfunction of female diabetic rats. PloS one, 7: e50402, 2012.

16- KHAKSAR S., KESMATI M., REZAIE A. and RASEKH A.: Effects of systemic and topical estrogen application on the healing of full-thickness skin wounds in diabetic rats. Comparative Clinical Pathology, 21: 653-9, 2012.

17- TOMODA K., WATANABE A., SUZUKI K., INAGI T., TERADA H. and MAKINO K.: Enhanced transdermal permeability of estradiol using combination of plga nanoparticles system and iontophoresis. Colloids and Surfaces B: Biointerfaces, 97: 84-9, 2012.

18- PRENTICE W.: Therapeutic modalities in rehabilitation, fourth edition: McGraw-Hill Education, 2011.

19- ESSA E.A., BONNER M.C. and BARRY B.W.: Iontophoretic estradiol skin delivery and tritium exchange in ultradeformable liposomes. International Journal of Pharmaceutics, 240: 55-66, 2002.

20- ARORA S., VEVES A., CABALLARO A.E., SMAKOWSKI P. and LoGERFO F.W.: Estrogen improves endothelial function. Journal of Vascular Surgery, 27: 1141-7, 1998.

21- NAKAGAWA H., AKITA S., FUKUI M., FUJII T. and AKINO K.: Human mesenchymal stem cells successfully improve skin-substitute wound healing. British Journal of Dermatology, 153: 29-36, 2005.

22- FATHKE C., WILSON L., HUTTER J., KAPOOR V., SMITH A., HOCKING A., et al.: Contribution of bone marrow-derived cells to skin: Collagen deposition and wound repair. Stem Cells, 22: 812-22, 2004.

23- ICHIOKA S., KOURABA S., SEKIYA N., OHURA N. and NAKATSUKA T.: Bone marrow-impregnated collagen matrix for wound healing: Experimental evaluation in a microcirculatory model of angiogenesis, and clinical experience. British Journal of Plastic Surgery, 58: 112430, 2005.

24- FALANGA V., IWAMOTO S., CHARTIER M., YUFIT T., BUTMARC J., KOUTTAB N., et al.: Autologous bone marrow-derived cultured mesenchymal stem cells delivered in a fibrin spray accelerate healing in murine and human cutaneous wounds. Tissue Engineering, 13: 1299312, 2007.

25- WU Y., CHEN L., SCOTT P.G. and TREDGET E.E.: Mesenchymal stem cells enhance wound healing through differentiation and angiogenesis. Stem Cells, 25: 264859, 2007.

26- HOCKING A.M. and GIBRAN N.S.: Mesenchymal stem cells: Paracrine signaling and differentiation during cutaneous wound repair. Experimental Cell Research, 316 : 2213-9, 2010

27- ARNO A.I., AMINI-NIK S., BLIT P.H., AL-SHEHAB M., BELO C., HERER E., et al.: Human wharton's jelly mesenchymal stem cells promote skin wound healing through paracrine signaling. Stem Cell Research \& Therapy, 5: 28, 2014.

28- RIBEIRO J., PEREIRA T. , AMORIM I., CASEIRO A.R., LOPES M.A., LIMA J., et al.: Cell therapy with human mscs isolated from the umbilical cord wharton jelly associated to a pva membrane in the treatment of chronic skin wounds. International Journal of Medical Sciences, 11: 979, 2014.

29- MENESES J.V.L., FORTUNA V., SOUZA E.S., DALTRO G.C., MEYER R., MINNITI C.P., et al.: Autologous stem cell-based therapy for sickle cell leg ulcer: A pilot study. British Journal of Haematology, 175: 949-55, 2016.

30- OTERO-VIÑAS M. and FALANGA V.: Mesenchymal stem cells in chronic wounds: The spectrum from basic to advanced therapy. Advances in Wound Care, 5: 14963, 2016. 


\section{تآثير توصيل الإستروجين بالتيار الكهربى مع العلاج بالخالايا الجذاعية الهابة مقابل

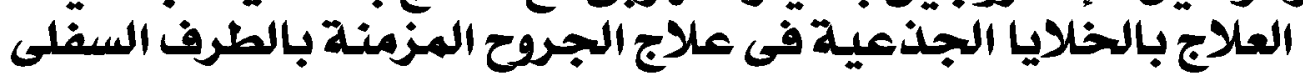

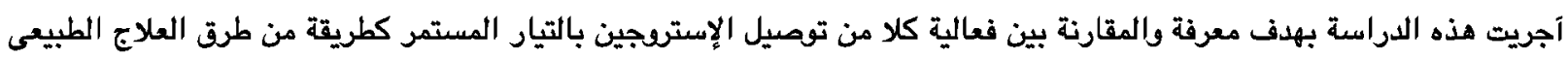

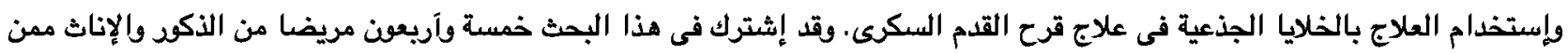

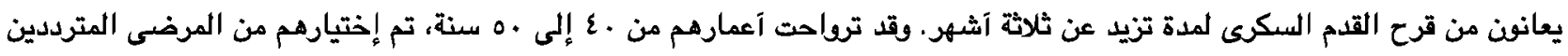

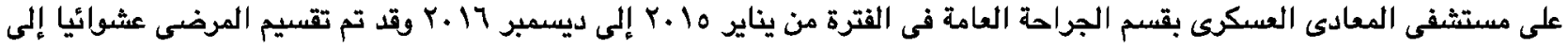

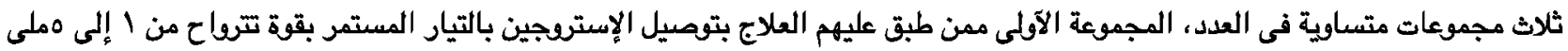

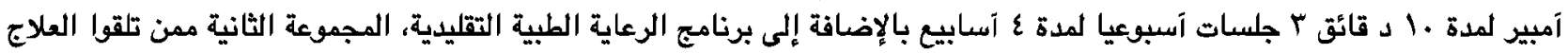

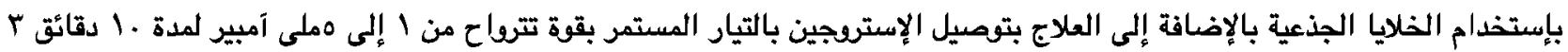

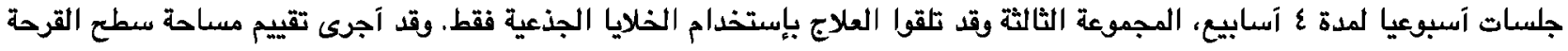

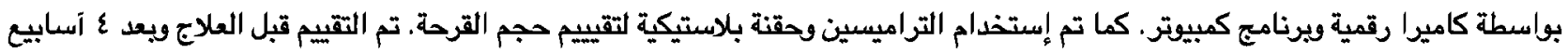

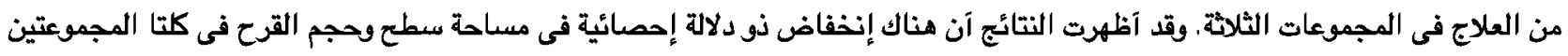

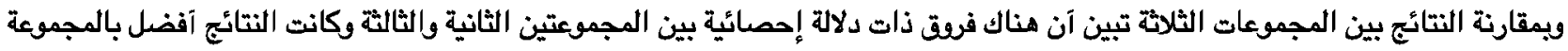

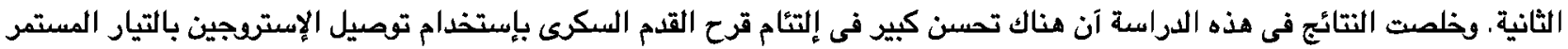

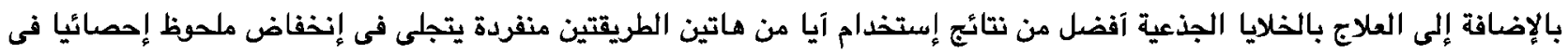

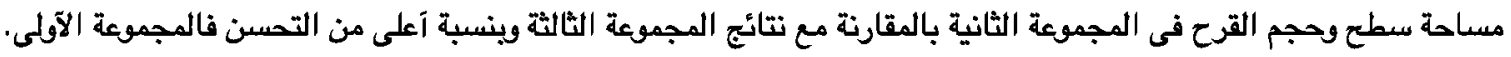

